\title{
Valproate: Past, Present, and Future
}

\author{
Cecilie U. Johannessen ${ }^{1}$ and Svein I. Johannessen ${ }^{2}$ \\ ${ }^{1}$ University College of Oslo, Oslo; \\ ${ }^{2}$ The National Center for Epilepsy, Sandvika, Norway
}

Key words: Anticonvulsants_-Epilepsy_-Valproate.

\begin{abstract}
Preclinical studies have been carried out during the past four decades to investigate the different mechanisms of action of valproate (VPA). The mechanisms of VPA which seem to be of clinical importance include increased GABAergic activity, reduction in excitatory neurotransmission, and modification of monoamines. These mechanisms are discussed in relation to the various clinical uses of the drug. VPA is widely used as an antiepileptic drug with a broad spectrum of activity. In patients, VPA possesses efficacy in the treatment of various epileptic seizures such as absence, myoclonic, and generalized tonicclonic seizures. It is also effective in the treatment of partial seizures with or without secondary generalization and acutely in status epilepticus.

The pharmacokinetic aspects of VPA and the frequent drug interactions between VPA and other drugs are discussed. The available methods for the determination of VPA in body fluids are briefly evaluated.

At present, investigations and clinical trials are carried out and evaluated to explore the new indications for VPA in other conditions such as in psychiatric disorders, migraine and neuropathic pain. Furthermore, the toxicity of VPA, both regarding commonly occurring side effects and potential idiosyncratic reactions are described. Derivatives of VPA with improved efficacy and tolerability are in development.
\end{abstract}

\section{INTRODUCTION}

Valproic acid (N-dipropylacetic acid) or valproate (VPA) is a unique drug, as it is a simple branched-chained fatty acid, structurally unrelated to any other antiepileptic drug

Address correspondence and reprint requests to: Dr. Cecilie U. Johannessen, c/o Dr. Svein I. Johannessen, Director of Research, The National Center for Epilepsy, P.O. Box 53, N-1306 Bærum Postterminal, Norway. Tel.: +47 (67) 55-41-69; Fax: +47 (67) 54-04-96; E-mail: svein.johannessen@epilepsy.no 


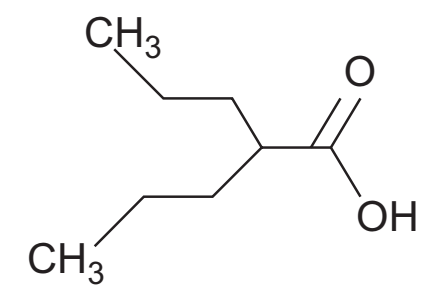

Fig. 1. The chemical structure of valproic acid, a simple branched-chained fatty acid.

(AED). Its antiepileptic properties were fortuitously discovered when it was used as a solvent for other compounds tested for antiepileptic activity four decades ago (92). VPA has been demonstrated to exert antiepileptic activities in a number of animal models of tonic-clonic, partial, and absence seizures (for review, see 79,80). VPA is a widely used AED since it possesses efficacy in the treatment of various seizure types such as absences, myoclonic, and generalized tonic-clonic seizures $(13,15,53)$. The drug has shown efficacy in the treatment of partial seizures with or without secondary generalization $(85,104)$. VPA is also effective in the acute treatment of status epilepticus (103). Consequently, VPA is a drug with a broad antiepileptic spectrum. In addition, VPA is extensively used in the treatment of bipolar disorders (17) and in other neurological conditions such as migraine and neuropathic pain (for review see 60).

\section{PHARMACOLOGY}

\section{Mechanisms of Action}

VPA has been thoroughly investigated, but still many aspects of the contribution of the proposed mechanisms remain uncertain.

\section{Effects of VPA on GABA and inhibitory neurotransmission}

As demonstrated by several studies, VPA potentiates GABAergic inhibitory effects in the central nervous system (CNS). The effect of VPA on GABA levels and enzymes related to the cerebral tricarboxylic acid (TCA) cycle has been investigated in vitro during the past three decades; it has been thoroughly reviewed by Löscher (79-81). In vitro VPA has been shown to inhibit GABA transaminase, succinic semialdehyde dehydrogenase, and $\alpha$-ketoglutarate dehydrogenase $(44,77,118)$. Consequently brain levels of GABA tend to increase acutely $(9,21,62)$. As discussed by Löscher $(80)$, GABA turnover is elevated in certain brain areas which are important in seizure inititation and propagation, such as the substantia nigra. A recent study by Petroff et al. (102) using ${ }^{1} \mathrm{H}-\mathrm{NMR}$ spectroscopy shows that VPA does not significantly increase brain GABA in patients with refractory complex partial seizures in the occipital cortex. The GABA elevating effect of VPA may, therefore, be of clinical importance primarily during acute treatment. Another possibility is that local changes in GABA are not detected, but further studies will hopefully differentiate and detect these local changes. 
In addition, VPA also interacts with the metabolism of $\gamma$-hydroxybutyrate (GHB), a metabolite of GABA. A reduction in GHB release could be of importance in the antiabsence effect of VPA $(81,119)$. It should be kept in mind, however, that the brain concentration of GHB is very low, and that there will be an equilibrium between GABA-succinic semialdehyde-GHB in the normal state (119).

The influence on the balance between GABA and glutamate may be involved in the action of VPA in the treatment of migraine, since VPA is likely to modulate the biochemical phenomenon of aura or to affect nociception by modulation of GABA and/or glutamate-mediated neurotransmission (27). Most recently, it has been concluded that all AEDs used in the treatment of migraine share a common role in enhancing GABA-mediated inhibition (25). In neuropathic pain, VPA has been demonstrated to block neurogenic inflammation via $\mathrm{GABA}_{\mathrm{A}}$ receptor-mediated inhibition, possibly by modulation of trigeminal nociceptive neurons innervating the meninges (28).

\section{Effects of VPA on excitatory neurotransmission}

VPA suppresses NMDA-evoked depolarizations $(40,125)$. Furthermore, it blocks seizures induced by NMDA (29). In contrast, VPA has not been shown to affect responses mediated by other ionotropic glutamate receptors, the AMPA or kainate receptors (96). Potential effects of VPA on metabotropic receptors are not known. A VPA-induced reduction of glutamatergic excitatory neurotransmission by antagonism of NMDA-receptors may, therefore, be a relevant mechanism of VPA's antiepileptic effect. A reduction in excitatory neurotransmission may also be important in the treatment of manic episodes.

As demonstrated by ${ }^{13} \mathrm{C}$ nuclear magnetic resonance (NMR) spectroscopy in mice, the synthesis of glutamate is reduced after acute administration of VPA, which could lead to a decrease in glutamatergic neurotransmission (62). This decrease is accompanied by an increase in the synthesis of GABA (62). This effect seems to be potentially advantageous, since it will reduce excitability and will reestablish a balance between the excitatory amino acid neurotransmitter glutamate and the inhibitory amino acid neurotransmitter GABA. It has been suggested that the effect of VPA on glutamate release may be responsible for the antimanic effect of the drug (32). At therapeutic concentrations this effect, however, does not seem to be clinically relevant (Fig. 2).

Acutely, VPA decreases aspartate levels in whole rodent brain $(21,62)$. The role of aspartate as a candidate excitatory neurotransmitter has recently been discussed. It does not seem to fulfil the criteria for a quantitatively important excitatory neurotransmitter, since it is mainly synthesized in GABAergic neurons $(48,61)$.

\section{Effects of VPA on monoamines}

Changes in the levels of the monoamines may also contribute to the clinical effects observed during treatment with VPA. In depression, the monoamines serotonin and norepinephrine, are generally assumed to be key mediators. After chronic treatment of rodents with VPA $(200 \mathrm{mg} / \mathrm{kg})$ the brain levels of norepinephrine, dopamine and serotonin increased in some and decreased in other brain areas (91). Microdialysis studies in rats demonstrated an elevation of levels of serotonin and dopamine metabolites (5-hydroxyindoleacetic, homovanillic and dihydroxyphenylacetic acids) after treatment with VPA at appropriate doses (53). Furthermore, Horton et al. (53) showed that blockade of serotonin 
synthesis did not diminish the antiepileptic action of VPA. This observation suggested that the effect of VPA on serotonin may not be important for its efficacy in epilepsy. The connections between the pathophysiological mechanisms of migraine and the role of serotoninergic and GABAergic neurotransmission have recently been discussed by Silberstein (111). A possible link between glutamatergic and serotonergic neurotransmission may also be of pharmacological importance in bipolar disorders, since glutamatergic excitatory neurotransmission may be regulated presynaptically by several serotonin receptors $\left(5-\mathrm{HT}_{1 \mathrm{~A}, 2,3}\right)(46,86,87)$.

\section{Effects of VPA on ion channels}

VPA reduces epileptiform discharges by inhibiting high-frequency firing of neurons $(90,115)$. This effect may contribute to the efficacy of VPA in the treatment of epilepsy, where excessive high-frequency bursting of neuronal aggregates is seen (36). As many other AEDs VPA was thought to inhibit sodium channels. Chronic treatment with VPA has been postulated to upregulate cell surface expression of sodium channels (123). However, the importance of inhibition of voltage-gated sodium channels as an independent mechanism of action of VPA has been lately questioned $(2,62,79,81)$. Löscher (81) concluded, that there is no convincing evidence that at therapeutically relevant concentrations VPA blocks voltage-dependent sodium currents.

At concentrations higher than therapeutic, VPA may affect calcium and potassium channels by interfering with calcium entry into the cell and activating potassium conductance, which leads to a reduction in neuronal excitability (37). An explanation of the neurophysiological effects observed could be that the lipophilic VPA molecule at millimolar concentrations interferes with the cell membrane structure (81).

\section{Effects of VPA on cerebral glucose metabolism}

In patients with epilepsy VPA has been shown to decrease cerebral glucose metabolism $(39,73)$. This effect has been recently attributed to the inhibition of the TCA cycle, that was first shown in vivo in mice (62). Acutely, VPA inhibits $\alpha$-ketoglutarate dehydrogenase, a rate limiting step of the TCA cycle, which leads to the impairment of cerebral ATP production (62). Since inhibition of metabolism may lead to a reduction in neuronal excitability through modulation of sodium channels (26), inhibition of sodium conductance may be a consequence of a decrease in energy production (62). Epileptic seizures are associated with a massive increase in cerebral energy metabolism (20). A reduction in cerebral glucose metabolism must, therefore, be regarded as favorable in the treatment of epilepsy. Acutely, in the initial phase of the treatment of status epilepticus, this mechanism could contribute to the anticonvulsant effect of VPA. In contrast, in bipolar disorders and mania, a reduction in cerebral metabolism has been seen, and a positive clinical response leads to a further decrease in cerebral metabolism $(74,99,107)$. Therefore, the effect of VPA on cerebral glucose metabolism seems favorable also in these conditions. Since VPA reduces cerebral metabolism acutely, a possible application may also include prevention of excitotoxic effects caused by excessive glutamatergic neurotransmission. 


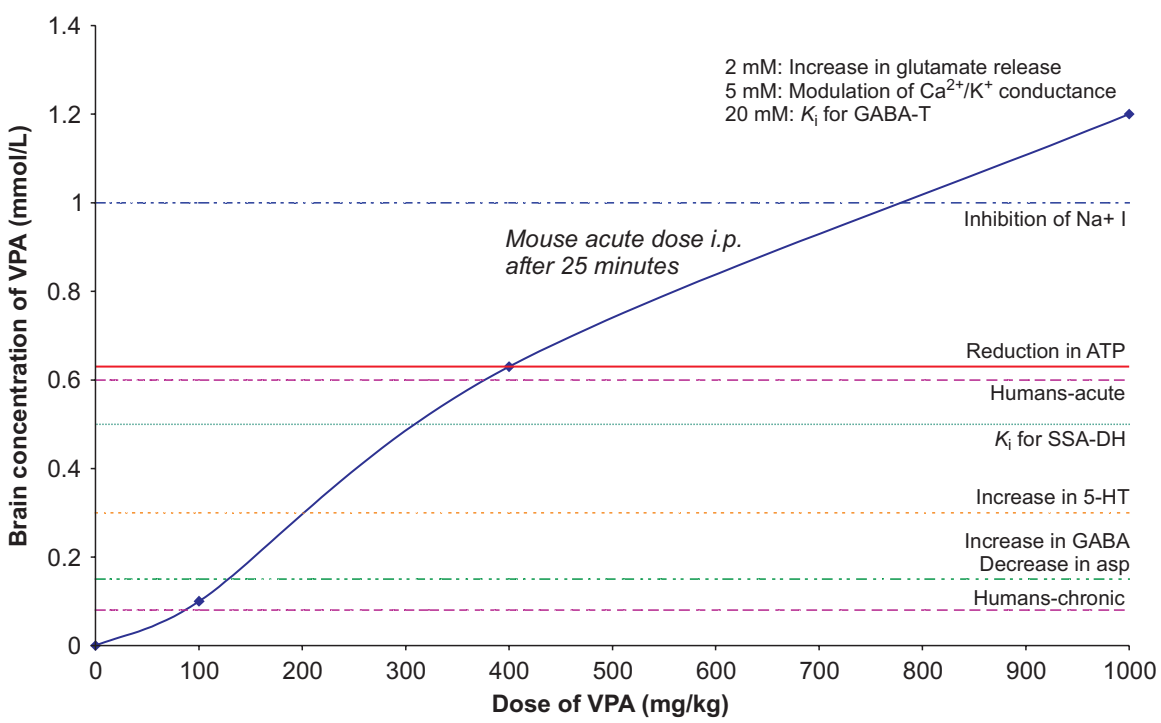

Fig. 2. A concentration-dependent model of mechanisms of action of VPA.

The figure illustrates the different mechanisms of actions related to doses administered acutely in vivo or concentrations used in in vitro experiments. The brain levels reached with acute and chronic VPA treatment in humans are calculated from serum levels reported in the literature $(21,79)$. The relationship between dose and actual brain level achieved is based on acute i. p. administration. of VPA at different doses in mice and measurement of brain levels at $25 \mathrm{~min}$ after sacrifice (Johannessen, unpublished). The following effects are observed with increasing brain levels of VPA: From the bottom: Effects on intracellular GABA and aspartate levels (from synaptosomes) are seen at a lower brain concentration of VPA than the extracellular effects of these amino acids $(21,79)$. Further effects are: Increase in serotonin and other monoamines (91), inhibition of succinic semialdehyde dehydrogenase (SSA-DH) (118), and decrease in ATP levels (Johannessen, unpublished; 62). The effects at even higher brain levels of VPA are: inhibition of sodium currents (I), increase in glutamate release (32), modulation of calcium and potassium conductance (37), and inhibition of GABA transaminase (GABA-T) (118).

\section{A concentration-dependent model for the mechanisms of action of VPA}

A model which summarizes the various mechanisms of action of VPA is presented in Fig. 2. The main targets for the action of VPA are correlated to the concentration curve of VPA following acute administration of the drug to mice. The mechanisms of action of VPA that most probably contribute to its clinical effects are illustrated. Figure 2 illustrates that at therapeutically relevant concentrations, effects of VPA on GABA metabolism and levels, serotonin levels and glucose metabolism seem to play a role. Effects of VPA on glutamate release, sodium, calcium, and potassium conductance, or GABA-T inhibition do not seem to contribute to the therapeutic effect of VPA.

Extrapolation from animals to humans and from in vitro studies to in vivo effects must, however, be regarded with caution. From rodents to humans there are major differences in the pharmacokinetics (79), but the brain concentrations achieved are comparable in mice and humans. It should also be noted that the mechanisms involved in the acute action of VPA at high concentrations given acutely during manic episodes or status epilepticus, may differ from the effects seen with chronic treatment. 
No single mechanism of action of VPA which is presented, can account for its numerous effects, but it seems likely that a combination of several effects may explain the broad spectrum of activity of VPA.

\title{
CLINICAL PHARMACOLOGY
}

\section{Pharmacokinetics}

\begin{abstract}
Absorption
The bioavailability of VPA is almost complete. It is 96 to $100 \%$ for all formulations of VPA in common use (conventional tablets, enteric coated tablets, sustained-release tablets, capsules, and oral and intravenous solutions). The rate of absorption, however, depends on the formulation. The time periods required to reach the peak serum concentrations of VPA vary with the formulations. With conventional tablets and solutions peak serum concentrations of VPA are reached at 1 to $2 \mathrm{~h}$ after administration, with enteric coated tablets at 3 to $6 \mathrm{~h}$, and with sustained-release tablets at 10 to $12 \mathrm{~h}$. The absorption of VPA is more rapid during maintenance therapy than after single doses. It is considerably delayed if the drug is taken at 2 to $3 \mathrm{~h}$ after meal, which may explain why absorption tends to be considerably slower in the afternoon than in the morning $(30,71)$.

VPA is rapidly absorbed by rectal application. Approximately the same serum concentrations of VPA can be obtained with rectally administered suppositories or solutions, as with oral medication (68). Rectal application offers, therefore, an alternative mode of administration when the drug cannot be given orally.
\end{abstract}

\section{Protein binding}

VPA is 78 to $94 \%$ bound to serum proteins. The binding is concentration-dependent, and if the serum concentration of VPA is above the therapeutic range $(>600 \mu \mathrm{mol} / \mathrm{L}$, $80 \mu \mathrm{g} / \mathrm{mL}$ ) binding may be as low as $67 \%(71)$. The protein bound fraction is less in patients with renal disease, chronic hepatic disease, in the elderly, during pregnancy and in the presence of other protein bound drugs such as phenylbutazone or acetylsalicylic acid. It is doubtful whether the binding of VPA is influenced by other AEDs (30). Unbound VPA concentrations in serum approximate those in CSF and tears $(63,94)$.

\section{Metabolism}

The half-life of VPA in serum is 11 to $20 \mathrm{~h}$. The drug is almost completely metabolized; only a small amount of unchanged VPA is found in the urine. The lowest values are found in the urine of patients treated with VPA and enzyme-inducing AEDs (30,71). The metabolism of VPA is independent of the serum concentration and follows first-order kinetics, suggesting that there is no auto-induction or saturation of the metabolism. Due to interindividual differences in metabolism there is a poor correlation between the dose of VPA and the serum concentration, especially in patients who are also taking enzyme-inducing AEDs (67). Children need considerably higher doses in $\mathrm{mg} / \mathrm{kg}$ body weight than adults to obtain comparable serum concentrations (66). The metabolism of VPA follows at least five main metabolic pathways including glucuronidation, $\beta$-oxidation, and $\Omega$-oxidation. However, the active metabolites represent only a minor percentage of the total 
serum VPA. The contributions of metabolites to the therapeutic and toxic effects of VPA are not fully understood. Alterations in the pharmacokinetics of VPA in the elderly are complex and involve a reduction in serum protein binding and drug metabolizing capacity. The dosage requirements may, therefore, be slightly lower in the elderly (30).

\section{Drug Interactions}

Pharmacokinetic interactions between VPA and other drugs are frequently seen, and several are of major clinical significance (Table 1). VPA inhibits the metabolism of a number of drugs and may easily result in intoxication if the dose of the co-medication is not reduced as shown for instance for phenobarbital and lamotrigine. Its own metabolism may also be stimulated by the enzyme-inducing activity of other AEDs, causing VPA levels to decrease. This is of considerable clinical significance, since it is often difficult to obtain satisfactory efficacy with VPA in patients who are treated also with phenytoin, phenobarbital, primidone, or carbamazepine $(30,49)$.

It is noteworthy that VPA does not diminish the effect or oral contraceptives, as is the case with enzyme-inducing AEDs. No interactions are seen between VPA and the combined oral contraceptive pill, progesterone-only pill, medroxyprogesterone injections or levonorgestrel implants (24).

\section{Drug Concentrations and Clinical Effects}

A therapeutic range for VPA in the order of 300 to $600 \mu \mathrm{mol} / \mathrm{L}$ (40 to $80 \mu \mathrm{g} / \mathrm{mL}$ ) has been suggested for patients with epilepsy, although this range must be regarded as only a rough guide $(30,45,49)$. Similar drug levels are recommended for patients with bipolar disorder (88). Because of the marked variability of serum levels over a $24 \mathrm{~h}$ period, blood samples should be drawn before the first dose of the day in order to ensure relative comparability of different determinations (66). The clinical effect of VPA may not be clearly cor-

TABLE 1. Pharmacokinetic interactions of VPA.

Effect on serum concentration

\begin{tabular}{ll}
\hline Drug & Effect \\
\hline Effects of VPA on other drugs & \\
Phenobarbital & Increased \\
Carbamazepine & Increased \\
Primidone & Increased \\
Ethosuximide & Increased \\
Lamotrigine & Increased \\
Felbamate & Increased \\
Oral contraceptives & No effect \\
Effects of other drugs on VPA & \\
Phenytoin & Decreased \\
Phenobarbital & Decreased \\
Carbamazepine & Decreased \\
Felbamate & Increased \\
\hline
\end{tabular}


related with the total serum levels since several factors influence this relationship. These factors include a relatively short half-life, diurnal variations in absorption and metabolism, and nonlinear protein binding (64). Due to interindividual differences in the protein binding of VPA, measurement of free drug levels instead of the total drug levels in serum serum has been suggested (30).

\section{Analytical Methods}

\section{Gas-liquid chromatography (GLC)}

As reviewed by Johannessen (64) most GLC procedures for determination of VPA involve formation of derivatives to produce volatile products with improved chromatographic characteristics and compounds with enhanced flame ionization detection. There are also several methods for quantitative analysis of metabolites of VPA by GLC or combined GLC-MS (mass spectroscopy). Some of the metabolites of VPA are of importance for the evaluation of adverse reactions. Lately, assessment of VPA concentrations in tears using GLC-MS, has been carried out, as a possibly useful method for therapeutic drug monitoring $(98,109)$. VPA concentrations in saliva samples have also been measured, but they do not seem to reflect the serum levels of the drug (76).

\section{High-performance liquid chromatography (HPLC)}

HPLC methods for the analysis of VPA are similar to the GLC methods, except that a liquid mobile phase is substituted for the gas phase, and a UV detector is used for the quantification of VPA. Reversed-phase, high performance columns, usually C-18, are used with mobile phases of either methanol and water or acetonitrile and water mixtures (64).

\section{Immunoassay methods}

Several immunoassay methods are now widely used for monitoring VPA because of their speed, simplicity, and sensitivity. These methods include EMIT (Syva/Dade Behring), SLFIA (Ames), FPIA (Abbott Diagnostics, Roche), CEDIA (Microgenics, Boehringer-Mannheim), and turbidimetric latex agglutination assay (Biotrack, Ciba-Corning). The analytical performance of these immunoassays appears to be practically equivalent to that of the chromatographic methods (64). The chemiluminescent analyser IMMULITE 2000 (Diagnostic Products) was recently shown to be similar to other immunoassays for VPA (38).

\section{CLINICAL STUDIES}

Today, VPA is widely used in the treatment of epilepsy. Current clinical trials with VPA are now focused mainly on new indications for the drug. The mechanism of action of VPA in several distinct clinical conditions is still largely unknown. It is conceivable, however, that the neuronal dysfunctions underlying these conditions are similar but are manifested in different locations or neuronal pathways of the central nervous system. The actions of 
VPA involving GABAergic, glutamatergic, and serotonergic neurotransmission may favorably contribute to the treatment of different neurological or psychiatric disorders.

\section{Epilepsy}

Various clinical studies over the last decades have demonstrated that VPA is effective in the treatment of many seizure types, including absence, tonic-clonic, and partial seizures. Both as add-on therapy and as monotherapy VPA is well-established as a first-line drug $(5,105$, for review, see 30,101$)$. In addition, it is also used to treat infantile spasms (West syndrome), Lennox-Gastaut syndrome, febrile seizures, and status epilepticus $(30,103)$. A microdialysis study in humans demonstrated the pharmacokinetic rationale for acute treatment with VPA. It is based on the rapid distribution of VPA to the brain (75). Recently, Marson et al. (83) performed a meta-analysis that compares VPA with carbamazepine in the monotherapy of epilepsy. The investigators concluded that there was no reason for the preference of VPA for generalized-onset seizures, while the preference for carbamazepine was supported in the case of partial-onset seizures (83). Recently, Perucca (101) reviewed prospective, randomized, comparative studies of VPA monotherapy and concluded that VPA can be distinguished from other AEDs by its broad spectrum of efficacy against all seizure types (for review, see 14,101).

\section{Bipolar Disorders}

VPA is regarded as a first choice drug in the treatment of bipolar disorders, including acute mania, cyclothymia, mixed state and rapid cycling $(70,72,88)$. Clinical trials have demonstrated that VPA is effective in manic phases of bipolar disorders, even in patients resistant to other drugs. VPA may also exert acute or long-term mood-stabilizing effects $(88,97)$. Patients in a mixed-state and rapid cyclers seem to respond better to VPA or carbamazepine than to lithium, but well documented, double-blind randomized studies are still needed to evaluate the long-term effectiveness of either drug (16). In the acute manic state of patients with bipolar or schizoaffective disorders, VPA is effective as short-term treatment with a rapid onset of action $(70,88)$. In these disorders, VPA seems to be more beneficial for patients with a seizure history or with abnormal neurological features (113). VPA may have less beneficial effects in acute depression than in acute mania, although administration of VPA over long periods of time seems to improve the efficacy (19).

Other possible indications for VPA include anxiety disorders, post-traumatic stress disorder, substance abuse, and schizophrenia. Because of its GABA-potentiating properties VPA may also be useful in the treatment of tardive dyskinesia (114).

\section{Migraine}

VPA has been shown to reduce the number of migraine attacks, as well as their duration and intensity in 50 to $70 \%$ of patients for periods of three months, up to one year or longer $(43,84,93,110,111)$. In the treatment of migraine VPA was used at doses of 200 to $1500 \mathrm{mg}$ a day (84). Safety of VPA in migraine prophylaxis was studied in an open long-term study by Silberstein et al. (112), and it showed that the initial benefits of VPA treatment with doses of $500 \mathrm{mg}$ per day were maintained for a period of three years. 


\section{Neuropathic Pain}

VPA has been approved for the treatment of trigeminal neuralgia (106). A phase II study to establish the efficacy and toxicity of VPA in patients with cancer-related neuropathic pain over a year was performed (47). The response rates varied in the trial, but many patients had a beneficial effect from the treatment. More controlled studies are, however, needed to evaluate the effects of VPA in various types of pain.

\section{TOXICITY}

\section{Dose-Related Side Effects}

Gastrointestinal side effects, e.g., nausea, vomiting, and gastrointestinal distress have been reported to occur in up to $25 \%$ of the patients (33), probably less with enteric-coated formulations. Weight gain is a frequent problem, and increase in body weight and body mass index following VPA treatment have recently been studied $(10,23)$. These studies show that weight gain occurs within the first ten weeks of treatment and is in the order of six kilograms $(10,23)$. Weight gain during VPA therapy is associated with metabolic changes like a decrease in $\beta$-oxidation of fatty acids (18), increased insulin and insulin/glucose ratios (31), and increased leptin and insulin levels (120). The problem appears to be more common in females, it is not necessarily eliminated by caloric restriction, and it may lead to discontinuation of VPA therapy.

Hair changes, like hair thinning, alopecia, sometimes regrowth of curly or differently colored hair may occur (47). These effects are probably dose-, or duration of therapy-related, so that dose reduction may help. There is a great individual susceptibility of patients to the development of tremor, which usually appears at doses within the therapeutic range (108). Beydoun et al. (5) measured safety of VPA in a double-blind monotherapy trial in partial epilepsy where the effects of VPA at a high-dose (555 to $1040 \mu \mathrm{mol} / \mathrm{L}, 80$ to $150 \mu \mathrm{g} / \mathrm{mL}$ ) and a low-dose (175 to $345 \mu \mathrm{mol} / \mathrm{L}, 25$ to $50 \mu \mathrm{g} / \mathrm{mL}$ ) were compared. The adverse events observed more frequently in the high-dose group included: tremor, thrombocytopenia, alopecia, asthenia, diarrhea, vomiting, and anorexia. With all drugs affecting central nervous system neurological side effects can be expected. They may include sedation, drowsiness, confusion and irritability; many of these side effects occur with polytherapy. There is a wide variability among patients in tolerance of VPA. VPA can produce some sedation at serum concentrations $>600 \mu \mathrm{mol} / \mathrm{mL}(80 \mu \mathrm{g} / \mathrm{mL})(107)$. VPA is regarded as a drug with a safe cognitive profile, but cognitive effects, including mild general psychomotor slowing may occur $(3,117,121)$.

Regarding metabolic disturbances, hyperammonemia is seen with VPA therapy, as a consequence of increased renal production of ammonia or inhibition of nitrogen elimination, or both $(51,52)$. Hyperammonemia may be enhanced in the presence of polytherapy $(122,124)$. Furthermore, VPA may induce hyperglycemia and hyperglycinuria $(58,95)$. In most patients, these changes are not associated with clinical symptoms and are detected by laboratory screening. Long-term VPA monotherapy may occasionally increase serum calcium concentrations and bone resorption, leading to decreased bone mineral density (110). 


\section{Idiosyncratic Reactions}

\section{Hematological toxicity}

VPA can cause direct bone marrow suppression leading to aplastic anemia or peripheral cytopenia affecting one or more cell lines. Occasional fatal bone marrow failure has been reported. Hematological toxicity of VPA varies in onset and severity, it is recurrent, transient, or persistent, and usually occurs at a high serum concentrations of VPA, but may be reversed with dose reduction. Discontinuation of therapy is rarely required (1). Thrombocytopenia, macrocytosis, neutropenia, and pure red cell aplasia can occur but are not reported to be life threatening (1). Potential adverse effects such as thrombocytopenia and leukopenia are detected by laboratory monitoring.

\section{Hepatotoxicity}

Regarding possible hepatotoxicity of VPA, transient elevations of hepatic enzymes without clinical symptoms are seen in 15 to $30 \%$ of patients (for review, see 4). VPA therapy has been associated with rare fatal hepatotoxicity, predominantly when used as part of polytherapy in young children under 2 years of age, where the incidence can be as high as 1:600, but with a rapidly decreasing incidence with increasing age and when used as monotherapy $(33,34,101)$. During the past years the occurrence of fatal liver toxicity has decreased, probably due to attention to the risk factors by physicians, patients or relatives, avoidance of high-risk groups, and monitoring of liver enzyme levels (101). Hypotheses regarding the pathogenesis of the hepatotoxicity include pre-existing neurological or physical defects, mitochondrial disease or inborn errors in metabolism, VPA inhibition of $\beta$-oxidation, and toxicity from VPA metabolites, such as 4-ene-VPA and 2,4-diene-VPA (4).

The occurrence of pancreatitis associated with VPA was recently reviewed, and it is regarded as a rare condition $(22,100)$. Its mechanism has not been established.

\section{Polycystic ovary syndrome}

Polycystic ovary syndrome is regarded as a controversial issue in women with epilepsy. The syndrome is characterized by endocrine dysfunction such as irregular menstruation or amenorrhoea, hirsutism and infertility, but its pathogenesis and clinical symptoms are heterogeneous, and the syndrome is also related to obesity, regardless of drug treatment (41). The question has been raised to which extent long-term treatment with VPA, obesity or epilepsy per se increases the frequency of polycystic ovary syndrome in women, and this issue has been hotly debated in a series of articles under the headline "Controversies of epilepsy" $(41,57,50)$. In summary, menstrual disorders, certain clinical, ultrasound or endocrine manifestations of disorders of the reproductive system, and polycystic ovary syndrome appear to be more common with VPA as compared to other AEDs (50). The incidence, clinical relevance, and influence of confounding factors remain to be evaluated in large, prospective randomized studies (50).

\section{Teratogenicity}

Teratogenicity may be a problem following treatment with VPA as well as with other AEDs. Neural tube defect, spina bifida, following the use of VPA was observed more than 20 years ago. The prevalence of neural tube defects is approximately $1-2.5 \%$ in offspring 
of mothers treated with VPA, especially on polytherapy during the first trimester of pregnancy. This incidence is significantly higher than with other AEDs (42). The role of folic acid metabolism is probably important in this context, and folic acid supplementation is recommended before and during pregnancy in all fertile women taking VPA and/or other AEDs (101). Since convulsive seizures are also considered harmful to the developing embryo, anticonvulsant prophylaxis is needed, choosing the AED that is most likely to control patients' seizures at a relatively low dose (101).

Based on animal models, high peak serum concentrations of VPA are likely to attenuate the teratogenic effects, possibly due to saturation of binding sites and increased unbound fraction of VPA. The use of slow-release preparations and dividing the daily dose into several doses is, therefore, recommended $(30,116)$. Women treated with VPA who become pregnant, are commonly considered to be at risk for complications during pregnancy or lactation, including teratogenic effects, direct neonatal toxicity, and the potential for long-term neurobehavioral sequelae (54). The therapy with VPA requires, therefore, attention to the timing of exposure, dosage, duration of use, and fetal susceptibility.

\section{DEVELOPMENT OF VPA DERIVATIVES}

Several derivatives of the VPA are now being tested in an attempt to develop VPA-like compounds with improved efficacy and reduced toxicity. One example of rational drug design is SDP421 (DP-VPA), a phospholipid prodrug of VPA, which is designed to enter the central nervous system where VPA is thought to be cleaved off at the site of seizure by increased phospholipase $\mathrm{A}_{2}$ activity. There is evidence that the activity of phospholipases is elevated at the site of paroxysmal neuronal activity (7). Partial and generalized seizures, not including absence seizures, are thought to be prevented by SPD421, as shown in preclinical models (8). It is expected that with SPD421 the targeted, demand-regulated delivery of VPA will provide seizure control with a lower systemic exposure to VPA and a reduced risk of central and systemic side effects (7). SPD421 seems to be more potent and longer acting than VPA in some models of chemically induced and genetic epilepsy, and it is well tolerated in several animal models acutely and chronically $(7,8)$. SPD421 is now being evaluated in the clinic. Phase I studies have been completed in 117 healthy volunteers with doses from 300 to $2400 \mathrm{mg}$ for up to 14 days and the drug has been well tolerated (8). Phase II studies to investigate efficacy and tolerability of SPD421 at various doses in the patient population are ongoing (8).

Several derivatives of VPA have been synthesized and tested for anticonvulsant potency. Valrocemide (N-valproyl glycinamide, TV 1901) was developed from a pharmacokinetic-based design of a series of N-valproyl derivatives of GABA and glycine with better penetration through the blood-brain barrier and a non-toxic metabolic pathway (8). Valrocemide has been demonstrated to be effective in several chemically and electrically induced seizure models (55), and it has a good safety profile (56). Valrocemide showed no teratogenic potency in animal models, in contrast to VPA (8). Valrocemide has been studied in humans in phase I studies $(6,7)$ and as add-on therapy in patients with epilepsy for 13 weeks with doses up to $2000 \mathrm{mg}$ a day with good safety, tolerability, and preliminary efficacy (8).

In the search for new drugs with a safe tolerability profile, several other analogs of VPA have been tested for their teratogenic properties, since their teratogenicity appears to 
vary with minor changes in their chemical structure (104). The analogs valnoctamide, valpromide, and valnoctic acid have been shown in mice to be distinctly less teratogenic than VPA itself (104). It must be noted, however, that no animal models have yet been proven to predict human teratogenicity.

Recently, the possible antitumor effects of VPA and its analogues were discussed in relation to the mechanisms responsible for the teratogenic effects of VPA. Same mechanism may conceivably be responsible for both effects (11). Several cellular effects of VPA have been demonstrated both on transcription factors and gene expression regulated by protein kinases, in addition to intracellular receptors and enzymes (12). These findings open new insights into future antitumor therapy.

\section{CONCLUSIONS}

During the past four decades many possible mechanisms of action of VPA have been explored. These investigations provide new insight into the broad spectrum of VPA activity. It seems reasonable that VPA acts through several distinct mechanisms involving different neurotransmitters. In addition, the activity of VPA appears to be related to the pathophysiological mechanisms involved in epilepsy as well as in several other neurological and psychiatric conditions. At present, clinical studies are ongoing to evaluate the efficacy and safety of VPA in bipolar disorders, migraine, and neuropathic pain. New derivatives of VPA with improved efficacy and tolerability are currently in development.

\section{REFERENCES}

1. Acharya S, Bussel JB. Hematologic toxicity of sodium valproate. J Pediatr Hematol Oncol 2000;22:62-65.

2. Albus A, Williamson R. Electrophysical analysis of the action of valproate on pyramidal neurons in the rat hippocampal slice. Epilepsia 1998;39:124-139.

3. Aldenkamp AP. Effects of antiepileptic drugs on cognition. Epilepsia 2001;42(Suppl 1):46-49.

4. Anderson GD. Children versus adults: Pharmacokinetic and adverse-effect differences. Epilepsia 2002; 43(Suppl 3):53-59.

5. Beydoun A, Sackellares JC, Shu V. Safety and efficacy of divalproex sodium monotherapy in partial epilepsy: A double-blind, concentration-response design clinical trial. Depakote monotherapy for partial seizures study group. Neurology 1997;48:182-188.

6. Bialer M, Johannessen SI, Kupferberg HJ, Levy RH, Loiseau P, Perucca E. Progress report on new antiepileptic drugs: A summary of the Fourth Eilat conference (EILAT IV). Epilepsy Res 1999;34:1-41.

7. Bialer M, Johannessen SI, Kupferberg HJ, Levy RH, Loiseau P, Perucca E. Progress report on new antiepileptic drugs: A summary of the Fifth Eilat conference (EILAT V). Epilepsy Res 2001;43:11-58.

8. Bialer M, Johannessen SI, Kupferberg HJ, Levy RH, Loiseau P, Perucca, E. Progress report on new antiepileptic drugs: A summary of the Sixth Eilat conference (Eilat VI). Epilepsy Res 2002;51:31-71.

9. Biggs CS, Pearce BR, Fowler LJ, Whitton PS. The effect of sodium valproate on extracellular GABA and other amino acids in the rat ventral hippocampus: An in vivo microdialysis study. Brain Res 1992;594: $138-142$.

10. Biton V, Mirza W, Montouris G, Voung A, Hammer AE, Barrett PS. Weight change associated with valproate and lamotrigine monotherapy in patients with epilepsy. Neurology 2001;56:172-177.

11. Blaheta RA, Cinatl J Jr, Anti-tumor mechanisms of valproate: A novel role of an old drug. Med Res Rev 2002;22:492-511. 
12. Blaheta RA, Nau H, Michaelis M, Cinatl J, Jr. Valproate and valproate analogues: Potent tools to fight against cancer. Curr Med Chem 2002;9:1417-1433.

13. Bourgeois B, Beaumanoir A, Blajev B, et al. Monotherapy with valproate in primary generalized epilepsies. Epilepsia 1987;28(Supp1 2):S8-S11.

14. Bourgeois B. Valproic acid. Clinical efficacy and use in epilepsy. In: Levy RH, Mattson RH, Meldrum BS, Perucca E, Eds. Antiepileptic drugs. 5th Edition. Philadelphia: Lippincott Williams \& Wilkins, 2002; 808-817.

15. Braathen G, Theorell K, Persson A, Rane A. Valproate in the treatment of absence epilepsy in children: A study of dose-response relationships. Epilepsia 1988;29:548-552.

16. Brambilla P, Barale F, Soares JC. Perspectives on the use of anticonvulsants in the treatment of bipolar disorder. Int J Neuropsychopharmacol 2001;4:421-446.

17. Brennan NJW, Sandyk R, Borsook D. Use of sodium valproate in the management of affective disorders: basic and clinical aspects. In: Okuma T, Müller AA, Eds. Anticonvulsants in affective disorders. Amsterdam: Emrich Excerpta Medica, 1994;56-65.

18. Breum L, Astrup A, Gram L, et al. Metabolic changes during treatment with valproate in humans: Implications for weight gain. Metabolism 1992;41:666-670.

19. Calabrese JR, Markowitz P, Kimmel SE, Wagner SC. Spectrum of efficacy of valproate in 78 rapid-cycling bipolar patients. J Clin Psychopharmacol 1992;43:487-490.

20. Chapman AG. Cerebral energy metabolism and seizures. In: Pedley TA, Meldrum BS, Eds. Recent advances in epilepsy. Edinburgh: Churchill-Livingstone, 1985;19-63.

21. Chapman AG, Riley K, Evans MC, Meldrum BS. Acute effects of sodium valproate and $\gamma$-vinyl GABA on regional amino acid metabolism in the rat brain: Incorporation of $2-\left[{ }^{14} \mathrm{C}\right]$ glucose into amino acids. Neurochem Res 1982;7:1089-1109.

22. Chapman SA, Wacksman GP, Patterson BD. Pancreatitis associated with valproic acid: A review of the literature. Pharmacotherapy 2001;21:1549-1560.

23. Chengappa KN, Chalasani L, Brar JS, Parepally H, Houck P, Levine J. Changes in body weight and body mass index among psychiatric patients receiving lithium, valproate, or topiramate: An open-label, nonrandomized chart study. Clin Ther 2002;24:1576-1584.

24. Crawford P. Interactions between antiepileptic drugs and hormonal contraception. CNS Drugs 2002;16:263-272.

25. Corbo J. The role of anticonvulsants in preventive migraine therapy. Curr Pain Headache 2003;7:63-66.

26. Cummins TR, Jiang C, Haddad GG. Human neocortical excitability is decreased during anoxia via sodium channel modulation. J Clin Invest 1993;91:608-615.

27. Cutrer FM. Antiepileptic drugs: How they work in headache. Headache 2001;41(Suppl 1):S3-S10.

28. Cutrer FM, Moskowitz MA. The actions of valproate and neurosteroids in a model of trigeminal pain. Headache 1996;36:579-585.

29. Czuczwar SJ, Frey H-H, Löscher W. Antagonism of N-methyl-D,L-aspartatic acid-induced convulsions by antiepileptic drugs and other agents. Eur J Pharmacol 1985;108:273-280.

30. Davies R, Peters DH, McTravish D. Valproic acid: A reappraisal of its pharmacological properties and clinical efficacy in epilepsy. Drugs 1994;47:332-372.

31. Demir E, Aysun S. Weight gain associated with valproate in childhood. Pedriatr Neurol 2000;22:361-364.

32. Dixon JF, Hokin LE. The antibipolar drug valproate mimics lithium in stimulating glutamate release and inositol 1,4,5-triphosphate accumulation in brain cortex slices but not accumulation of inositol monophosphates and biphosphates. Proc Natl Acad Sci USA 1997;94:4757-4760.

33. Dreifuss FE, Santilli N, Langer DH, Sweeney KP, Moline KA, Menander KB. Valproic hepatic fatalities: A retrospective review. Neurology 1987;37:379-385.

34. Dreifuss FE, Langer DH, Moline KA, Maxwell JE. Valproic acid hepatic fatalities II: US experience since 1984. Neurology 1988;33:201-207.

35. Duncan S. Polycystic ovarian syndrome in women with epilepsy: A review. Epilepsia 2001;42(Suppl 3): 60-65.

36. Fariello RG, Varasi M, Smith MC. Valproic acid, mechanisms of action. In: Levy RH, Mattson RH, Meldrum BS, Eds. Antiepileptic drugs. 4th Edition. New York: Raven Press, 1995;581-588.

37. Franceschetti S, Hamon B, Heineman U. The action of valproate on spontaneous epileptiform activity in the absence of synaptic transmission and on evoked changes in $\left[\mathrm{Ca}^{2+}\right]_{0}$ and $\left[\mathrm{K}^{+}\right]_{0}$ in the hippocampal slice. Brain Res 1986;386:1-11.

38. Frank EL, Schwarz EL, Juenke J, Annesley TM, Roberts WL. Performance characteristics of four immunoassays for antiepileptic drugs on the IMMUNOLITE 2000 automated analyser. Am J Clin Pathol 2002;118: 124-131. 
39. Gaillard WD, Zeffiro T, Fazilat S, Decarli C, Theodore WH. Effect of valproate on cerebral metabolism and blood flow: An ${ }^{18} \mathrm{~F}-2$-deoxyglucose and ${ }^{15} \mathrm{O}$ water positron emission tomography study. Epilepsia 1996;37: 515-21.

40. Gean PW. Valproic acid suppresses the synaptic response mediated by the NMDA receptors in rat amygdalar slices. Brain Res Bull 1994;33:333-336.

41. Genton P, Bauer J, Duncan S et al. On the association between valproate and polycystic ovary syndrome. Epilepsia 2001;42:295-304.

42. Genton P, Gelisse P. Valproic acid. Adverse effects. In: Levy RH, Mattson RH, Meldrum BS, Perucca E, Eds. Antiepileptic drugs. 5th Edition. Philadelphia: Lippincott Williams \& Wilkins, 2002;837-851.

43. Ghose K, Niven B. Prophylactic sodium valproate therapy in patients with drug-resistant migraine. Methods Find Exp Clin Pharmacol 1998;20:353-359.

44. Godin Y, Heier L, Mark J, Mandel P. Effects of di-n-propylacetate, an anticonvulsant compound, on GABA metabolism. J Neurochem 1969;16:869-873.

45. Gram L, Flachs H, Würtz-Jørgensen A, Parnas J, Andersen B. Sodium valproate, serum levels and clinical effect in epilepsy: A controlled study. Epilepsia 1979;20:303-312.

46. Grünschlag CR, Haas HL, Stevens DR. 5-HT inhibits lateral entorhinal cortical neurons of the rat in vitro by activation of potassium channel-coupled 5-HT ${ }_{1 \mathrm{~A}}$ receptors. Brain Res 1997;770:10-17.

47. Hardy JR, Rees EA, Gwilliam B, Ling J, Broadley K, A'Hern R. A phase II study to esablish the efficacy and toxicity of sodium valproate in patients with cancer-related neuropathic pain. J Pain Symptom Manage 2001;21:204-209.

48. Hassel B, Sonnewald U. Selective inhibition of the tricarboxylic acid cycle of GABAergic neurons with 3-nitropropionic acid in vivo. J Neurochem 1995;65:1-8.

49. Henriksen O, Johannessen Si. Clinical and pharmacokinetic observations on sodium valproate-a 5-year follow-up study in 100 children with epilepsy. Acta Neurol Scand 1982;65:504-523.

50. Herzog AG, Schachter SC. Valproate and polycystic ovary syndrome: Final thoughts. Epilepsia 2001;42: 311-315.

51. Hjelm M, de Silva LV, Seakins JW, Oberholzer VG, Rolles CJ. Evidence of inherited urea cycle defect in a case of fatal valproate toxicity. Br Med J 1986;292:23-24.

52. Honeycutt D, Callahan K, Rutledge L, Wans B. Heterozygotic ornithine transcarbamylase deficiency presenting as symptomatic hyperammonemia during initiation of valproate treatment. Neurology 1992;42: 666-668.

53. Horton RW, Anlezark GM, Sawaya MC, Meldrum BS. Monoamine and GABA metabolism and the anticonvulsant action of di-n-propylacetate and ethanolamine-O-sulphate. Eur J Pharmacol 1977;41:387-397.

54. Iqbal MM, Sohhan T, Mahmud SZ. The effects of lithium, valproic acid, and carbamazepine during pregnancy and lactation. J Toxicol Clin Toxicol 2001;39:381-392.

55. Isoherränen N, Woodhead JH, White HS, Bialer M. Anticonvulsant profile of valrocemide (TV 1901): A new antiepileptic drug. Epilepsia 2001;42:831-836.

56. Isoherränen N, White HS, Finnell RH, Woodhead JH, Bennett GD, Bialer M. Anticonvulsant activity and teratogenicity of valrocemide (TV 1901). Epilepsia 2001;42(Suppl 7):212.

57. Isojärvi JI, Taubøll E, Tapanainen JS, et al. On the association between valproate and polycystic ovary syndrome: A response and an alternative view. Epilepsia 2001;42:305-310.

58. Jaeken J, Caesar P, Corbeel L. Valproate, hyperammonemia and hyperglycinaemia. Lancet 1980;2:260.

59. Jeavons PM. Non-dose-related side effects of valproate. Epilepsia 1984;25(Suppl 1):S50-S55.

60. Johannessen CU. Mechanisms of action of valproate: A commentatory. Neurochem Int 2000;37:103-110.

61. Johannessen CU, Qu H, Sonnewald U, Hassel B, Fonnum F. Estimation of aspartate synthesis in GABAergic neurons in mice by ${ }^{13} \mathrm{C}$ NMR spectroscopy. Neuroreport 2001;12:3729-32.

62. Johannessen CU, Petersen D, Fonnum F, Hassel B. The acute effect of valproate on cerebral energy metabolism in mice. Epilepsy Res 2002;47:247-56.

63. Johannessen SI. Preliminary observations on valproic acid kinetics in patients with epilepsy. Arzneimittelforschung 1977;27:1083-1085.

64. Johannessen SI. General principles. Methods of determination of antiepileptic drugs. In: Levy RH, Mattson RH, Meldrum BS, Eds. Antiepileptic drugs. 4th Edition. New York: Raven Press, 1995;243-70.

65. Johannessen SI. Plasma drug concentration monitoring of anticonvulsants. Practical guidelines. CNS Drugs 1997;7:349-65.

66. Johannessen SI, Henriksen O. Serum levels of di-n-propyl acetate in epileptic patients. Pharm Weekblad 1977;112:287-289.

67. Johannessen SI, Henriksen O. Pharmacokinetic observations of sodium valproate in healthy subjects and in patients with epilepsy. In: Johannessen SI, Morselli PL, Pippenger CE, Richens A, Schmidt D, Meinardi H, Eds. Antiepileptic therapy: Advances in drug monitoring. New York: Raven Press, 1980;131-140. 
68. Johannessen SI, Henriksen O, Munthe-Kaas AW, Salvesen B. Serum concentration profile studies of tablets and suppositories of valproate in healthy subjects and in patients with epilepsy. In: Johannessen SI, Morselli PL, Pippenger CE, Richens A, Schmidt D, Meinardi H, Eds. Metabolism of antiepileptic drugs. New York: Raven Press, 1984;61-71.

69. Jones TH. Sodium valproate-induced menstrual disturbances in young women. Hormone Res 1991;35: 82-85.

70. Keck PE, Jr., McElroy SL, Tugrul KC, Bennett JA. Valproate loading dose in the treatment of acute mania. J Clin Psych 1993;54:305-308.

71. Klotz U, Antonin KH. Pharmacokinetics and bioavailability of sodium valproate. Clin Pharmacol Ther 1977;21:736-743.

72. Kusamakar V, Yatham LN, Haslam DR, et al. Treatment of mania, mixed state, and rapid cycling. Can $J$ Psych 1997; 42(Suppl 2):79S-86S.

73. Leiderman DB, Balish M, Bromfield EB, Theodore WH. Effect of valproate on human cerebral glucose metabolism. Epilepsia 1991;32:417-422.

74. Leuchter AF, Cook IA, Uitjdehaage SH, et al. Brain structure and function and the outcomes of treatment for depression. J Clin Psych 1997;58:22-31.

75. Lindberger M, Tomson T, Wallstedt L, Stahle L. Distribution of valproate to subdural cerebrospinal fluid, subcutaneous extracellular fluid, and plasma in humans: A microdialysis study. Epilepsia 2001;26:256-261.

76. Liu H, Delgado MR. Therapeutic drug concentration monitoring using saliva samples. Focus on anticonvulsants. Clin Pharmacokinet 1999;36:453-470.

77. Luder AS, Parks JK, Frerman F, Parker WD. Inactivation of beef brain $\alpha$-ketoglutarate dehydrogenase complex by valproic acid and valproic acid metabolites. Am Soc Clin Invest 1990;86:1574-1581.

78. Löscher W. Valproate induced changes in GABA metabolism at the subcellular level. Biochem Pharm 1981; 30:1364-1366.

79. Löscher W. Valproate: A reappraisal of its pharmacodynamic properties and mechansisms of action. Prog Neurobiol 1999;58:31-59.

80. Löscher W. Basic pharmacology of valproate: A review after 35 years of clinical use for the treatment of epilepsy. CNS Drugs 2002;16:669-694.

81. Löscher W. Valproic acid. Mechanisms of action. In: Levy RH, Mattson RH, Meldrum BS, Perucca E, Eds. Antiepileptic drugs. 5th Edition. Philadelphia: Lippincott Williams \& Wilkins, 2002;767-779.

82. Margraf JW, Dreifuss FE. Amenorrhea following initiation of therapy with valproic acid. Neurology 1981;31:159.

83. Marson AG, Williamson PR, Clough H, Hutton JL, Chadwick DW. Carbamazepine versus valproate monotherapy for epilepsy: A meta-analysis. Epilepsia 2002;43:505-513.

84. Mathew NT. Antiepileptic drugs in migraine prevention. Headache 2001;41(Suppl 1):S18-S24.

85. Mattson RH, Cramer JA, Collins JF. A comparison of valproate and carbamazepine for the treatment of complex partial seizures and secondarily generalised tonic-clonic seizures in adults. N Engl J Med 1992;327: 765-771.

86. Maura G, Carbone R, Guido M, Pestarino M, Raiteri M. 5- $\mathrm{HT}_{2}$ presynaptic receptors mediate inhibition of glutamate release from cerebellar mossy fibre terminals. Eur J Pharmacol 1991;202:185-190.

87. Maura G, Marcoli M, Tortarolo M, Androli GC, Raiteri M. Glutamate release in human cerebral cortex and its modulation by 5-hydroxytyramine acting at 5-HT ${ }_{1 \mathrm{D}}$ receptors. Br J Pharmacol 1998;123:45-50.

88. McElroy SL, Keck PE, Jr., Tugrul KC, Bennett JA. Valproate as a loading treatment in acute mania. Neuropsychobiology 1993;27:146-149.

89. McElroy SL, Keck PE, Jr. Experience with valproate in affective disorders. In: Modingh K, Robak OH, Vestergaard P, Eds. Anticonvulsants in psychiatry. Petersfield: Wrightson Biomedical Publishing, 1994; 57-72.

90. McLean MJ, Macdonald RL. Sodium valproate, but not ethosuximide, produces use- and voltage-dependent limitation of high frequency repetitive firing of action potentials of mouse central neurons in cell culture. J Pharmacol Exp Ther 1986;237:1001-1011.

91. Meshki-Baf MH, Subhash MN, Madepalli Lakshamana K, Sridhara Rama Rao BS. Sodium valproate induced alterations in monoamine levels in different regions of the rat brain. Neurochem Int 1994;1:67-72.

92. Meunier H, Carraz G, Meunier Y, Eymard P, Aimard M. Properiètès pharmacodynamiques de lìacide n-dipropylacetique. Therapie 1963;18:435-438.

93. Mitsikostas D, Polychronidis I. Valproate versus flunarizine in migraine prophylaxis: A randomised, double-open, clinical trial. Func Neurol 1997;12:267-276.

94. Monaco F, Piredda S, Mutani R, Mastropaolo C, Tondi M. The free fraction of valproic acid in tears, saliva, and cerebrospinal fluid. Epilepsia 1982;23:23-26. 
95. Mortensen PB, Koluraa S, Christensen, E. Inhibition of the glycine cleavage system: Hyperglycinemia and hyperglycinuria caused by valproic acid. Epilepsia 1980;21:563-69.

96. Musshoff U, Madeja M, Düsing R, et al. Valproate affects glutamate but not GABA receptors. Eur $J$ Neurosci 1996;9(Suppl):205.

97. Muzina DJ, El-Sayegh S, Calabrese JR. Antiepileptic drugs in psychiatry-focus on randomised controlled trial. Epilepsy Res 2002;50:195-202.

98. Nakajima M, Yamato S, Shimada K, et al. Assessment of drug concentrations in tears in therapeutic drug monitoring: I. Determination of valproic acid in tears by gas chromatography/mass spectrometry with EC/NCI mode. Ther Drug Monit 2000;22:716-722.

99. Nobler MS, Sackeim HA, Prophovnik I, et al. Regional cerebral blood flow in mood disorders. III. Treatment and clinical response. Arch Gen Psych 1994;51:884-897.

100. Pellock JM, Wilder BJ, Deaton R, Sommerville KW. Acute pancreatitis coincident with valproate use: A critical review. Epilepsia 2002;43:1421-1424.

101. Perucca E. Pharmacological and therapeutic properties of valproate. A summary after 35 years of clinical experience. CNS Drugs 2002;16:695-714.

102. Petroff OAC, Rothman DL, Behar KL, Hyder F, Mattson RH. Effects of valproate and other antiepileptic drugs on brain glutamate, glutamine, and GABA in patients with refractory complex partial seizures. Seizure 1999;8:120-127.

103. Price DJ. Intravenous valproate: Experience in neurosurgery. In: Chadwick D, Ed. Fourth international symposium on sodium valproate and epilepsy. London: Royal Society of Medicine Services, 1989; 197-203.

104. Radatz M, Ehlers K, Yagen B, Bialer M, Nau H. Valnoctamide, valpromide and valnoctic acid are much less teratogenic in mice than valproic acid. Epilepsy Res 1998;30:41-48.

105. Richens A, Davidson DLW, Cartlidge, Easter DJ. A multicentre comparative trial of sodium valproate and carbamazepine in adult onset epilepsy. J Neurol Neurosurg Psych 1994;57:682-687.

106. Ross EL. The evolving role of antiepileptic drugs in treating neuropathic pain. Neurology 2000; 55(Suppl 1):S41-46.

107. Rowan AJ. Valproate. In: Engel J, Jr., Pedley TA, Eds. Epilepsy: A comprehensive textbook. Philadelphia: Lippincott-Raven Publishers, 1997;1599-1607.

108. Rubin E, Sackeim HA, Prohovnik I, Moeller JR, Schnur DB, Mukherjee S. Regional cerebral blood flow in mood disorders: IV. Comparison of mania and depression. Psych Res 1995;61:1-10.

109. Sato S, Kitagawa S, Nakajima M, Shimada K, Honda A, Miyazaki H. Assessment of tear concentrations on therapeutic drug monitoring. II. Pharmacokinetic analysis of valproic acid in guinea pig serum, cerebrospinal fluid, and tears. Pharm Res 2001;18:500-509.

110. Sato Y, Kondo I, Ishida S, et al. Decreased bone mass and increased bone turnover with valproate therapy in adults with epilepsy. Neurology 2001;14:445-449.

111. Silberstein SD. Valproic acid. Clinical efficacy and use in other neurological disorders. In: Levy RH, Mattson RH, Meldrum BS, Perucca E, Eds. Antiepileptic drugs. 5th Edition. Philadelphia: Lippincott Williams \& Wilkins, 2002;818-827.

112. Silberstein SD, Collins SD. Safety of divalproex sodium in migraine prophylaxis: An open-term study. Long-term safety of Depakote in headache prophylaxis study group. Headache 1999;39:633-643.

113. Stoll AL, Banov M, Kolbrener M. Neurologic factors predict a favorable valproate response in schizoaffective disorders. J Clin Psychopharmacol 1994;14:311-313.

114. Swann AC. Valproic acid. Clinical efficacy and use in psychiatric disorders. In: Levy RH, Mattson RH, Meldrum BS, Perucca E, Eds. Antiepileptic drugs. 5th Edition. Philadelphia: Lippincott Williams \& Wilkins, 2002;828-836.

115. Thomas AB, Mathews GC, Ferrendelli JA. Mechanisms of action of antiepileptic drugs. In: Wyllie E, Ed. The treatment of epilepsy: Principles and practice. 2nd Edition. Baltimore: Williams \& Wilkins, 1996; 700-711.

116. Tomson T, Gram L, Sillanpää M, Johannessen SI. Recommendations for the management and care of pregnant women with epilepsy. In: Tomson T, Gram L, Sillanpää M, Johannessen SI, Eds. Epilepsy and pregnancy. Petersfield: Wrightson Biomedical Publishing, 1997;201-208.

117. Trimble MR, Thompson PJ. Sodium valproate and cognitive function. Epilepsia 1984;25(Suppl 1): S60-S64.

118. Van der Laan JW, De Boer T, Bruinvels J. Di-n-propylacetate and GABA degradation. Preferential inhibition of succinic semialdehyde dehydrogenase and indirect inhibition of GABA-transaminase. J Neurochem 1979;32:1769-1780.

119. Vayer P, Cash CD, Maitre M. Is the anticonvulsant mechanism of valproate linked to its interaction with the cerebral $\gamma$-hydroxybutyrate system? Trends Pharmacol Sci 1988;9:127-129. 
120. Verotti A, Basciani F, Moressi S, et al. Serum leptin changes in epileptic patients who gain weight after therapy with valproic acid. Neurology 1999;53:230-232.

121. Vining EPG. Cognitive dysfunction associated with antiepileptic drug therapy. Epilepsia 1987;28(Suppl 2): S18-S22.

122. Williams CA, Tiefenbach S, McReynolds JW. Valproic acid-induced hyperammonemia in mentally retarded adults. Neurology 1984;34:550-553.

123. Yamamoto R, Yanagita T, Kobayashi H, Yokoo, H, Wada A. Up-regulation of sodium channel subunit mRNAs and their cell surface expression by antiepileptic valproic acid: Activation of calcium channel and catecholamine secretion in adrenal chromaffin cells. J Neurochem 1997;68:1655-1662.

124. Zaccara G, Paganini M, Campostrini R, et al. Effect of associated antiepileptic treatment on valproate-induced hyperammonemia. Ther Drug Monit 1985;7:185-190.

125. Zeise ML, Kasparow S, Zieglgänsberger W. Valproate supresses N-methyl-D-aspartate-evoked, transient depolarizations in the rat neocortex in vitro. Brain Res 1991;544:345-348. 